\title{
DESAFIOS E TENDÊNCIAS DOS ESTUDOS SOBRE CIDADES PEQUENAS NO BRASIL
}

\author{
Aldenilson Costa \\ Doutorando em Planejamento Urbano e Regional \\ Instituto de Pesquisa e Planejamento Urbano e Regional \\ Universidade Federal do Rio de Janeiro \\ Email: alsvcosta@gmail.com
}

\section{RESUMO}

O objetivo é apresentar reflexões teóricas sobre estudos urbanos tomando como foco as cidades pequenas a partir da consideração da escala e contexto espacial no Brasil. Como metodologia parte-se da Literature Review sobre estudos de cidades pequenas nos estudos urbanos. Numa segunda parte tomamos a escala desde a qual conceituamos as cidades pequenas tanto do ponto de vista da estrutura da rede urbana como da perspectiva do espaço urbano. Assim, passamos a definição de dois contextos espaciais - urbanoindustrial e agroindustrial - para a abordagem das cidades pequenas que permite novas formas de conceituação deste tipo de cidade no Brasil.

Palavras-chave: organização do espaço, cidade pequena, escala, contexto espacial.

\begin{abstract}
The objective is to present theoretical reflections on the theory of urban studies focus on taking small towns from the consideration of the scale and spatial context in Brazil. As methodology was part of the Literature Review on small towns of studies in urban studies. In the second part we take the scale from which we conceptualize the small towns from the point of view of the structure of the urban network as the perspective of urban space. Thus we define two spatial contexts - urban-industrial and agribusiness - to address the small towns that enables new ways of conceptualizing this type of town in Brazil.
\end{abstract}

Key words: Space organization, small town, scale, spatial context 


\section{INTRODUÇÃO}

De acordo com o censo 2010 do IBGE, no Brasil, cerca de 33\% da população vive em cidades com até 50 mil habitantes (IBGE, 2010), isto é, cidades pequenas (Corrêa, 1999; Fresca, 2001). Esse cenário corresponde ao fato de que com o avanço da urbanização ocorre a concentração de pessoas, infraestrutura e investimentos em espaços metropolitanos e, posteriormente, em decorrência de políticas governamentais, em cidades médias. Já as cidades pequenas perdem progressivamente centralidade como apontam Santos (2008a), Corrêa (1999) e Endlich (2011). Isso implica na requalificação da função desempenhada e do sentido de cidade pequena.

No campo acadêmico os estudos urbanos concentram-se sobre os complexos núcleos metropolitanos (Santos, 2008a) e cidades médias (Maia, 2010), relegando às cidades pequenas estudos que por vezes limitam-se a constatação da perda de população e da função de confluência urbano-rural (Corrêa, 1999, 2011; Benitez, 2009; Endlich, 2011). Tal entendimento ao ser alvo de críticas orienta avanços analíticos e conceituais para o qual é importante destacar o papel do Simpósio Nacional sobre Pequenas Cidades (SINAPEQ) e do Simpósio Cidades Médias e Pequenas da Bahia. Tais encontros, que ocorrem periodicamente, possibilitam trocas de conhecimento, contribuindo para a mudança analítica e conceitual, pois, como argumenta Moreira Júnior (2014, p. 117) "não se pode generalizar e assumir a premissa de que todas as cidades pequenas possuem papéis urbanos pouco expressivos, predominantemente políticoadministrativos, com funções comerciais e agrárias".

Nesse sentido, Bell e Jayne (2009) afirmam que embora exista um punhado de metrópoles globais, a principal característica do mundo urbano é justamente a heterogeneidade. Os autores evidenciam a importância das cidades globais, mas argumentam que as cidades pequenas também contribuem no amplo processo de globalização. A partir dessa crítica reclamam a necessidade de considerar a cidade pequena no contexto da crise urbana, valorizando a maneira com que ela pode contribuir ao amplo desenvolvimento da sociedade.

Na tentativa de apreender a cidade pequena valorizando as suas características e papéis desempenhados, esforços de conceituação são realizados como os que encontramos em Santos (1979, 2007, 2008a), Maia (2010), Soares e Melo (2010), Corrêa (2011), Sposito e Silva (2014), Moreira Junior (2014) e outros. As análises realizadas por diferentes autores apontam para a necessidade de combinação de múltiplas variáveis na conceituação da cidade pequena.

Nosso objetivo é, pois, apresentar reflexões sobre a teoria dos estudos urbanos tomando como foco as cidades pequenas a partir da consideração da escala e contexto espacial no Brasil. Como metodologia parte-se da Literature Review sobre estudos de cidades pequenas nos estudos urbanos. Numa segunda parte tomamos a escala desde a qual conceituamos as cidades pequenas tanto do ponto de vista da estrutura da rede urbana como da perspectiva do espaço urbano. Assim, passamos a definição de dois contextos espaciais - urbano-industrial e agroindustrial - para a abordagem das cidades pequenas que permite novas formas de conceituação deste tipo de cidade no Brasil.

\section{O CONTRADITÓRIO PROCESSO DE URBANIZAÇÃO BRASILEIRO}

O processo de urbanização no Brasil é contraditório, por excelência, tanto pela velocidade quanto pelos resultados produzidos que, impulsionado pela recente industrialização, promove transformações na organização de cidades nas escalas inter e intra-urbana. O fenômeno de urbanização a partir dos anos 1950 tem uma virada, onde se anteriormente as cidades pequenas eram foco da dinâmica sócio-espacial (Corrêa, 2011), esse papel passa a ser exercido pelas metrópoles que funcionam como poderosos centros de gestão do território (Corrêa, 1996).

As metrópoles além de desenvolver funções de comando (Santos \& Silveira, 2001) atraem fluxos migratórios que respondem a concentração de investimentos, empregos, e recursos. Isso produz o inchaço urbano, com destaque para as cidades de São Paulo e Rio de Janeiro, cujos reflexos são observados na organização do espaço urbano com a intensificação das disparidades e desigualdades sociais, como argumenta Maia (2010). Por outro lado, as novas dinâmicas territoriais promovidas pelo processo de globalização contribuem a nova redistribuição do processo produtivo.

Acompanha estas transformações, que se processam de forma desigual em todo território nacional, o aprofundamento da metropolização; crescente valorização de estudos urbanos sobre as metrópoles e sobre cidades médias dada a complexidade que estas cidades passam a apresentar, bem como a importância destes centros na gestão do território; perda de centralidade das pequenas cidades que até a primeira 
metade do século XX apresentavam como centros importantes do porto de vista da organização econômica e social como assinalam Corrêa (2011) e Endlich (2011).

Como resultado, o conjunto de impulsos a que o território nacional está sujeito abre caminho para um sistema de cidades heterogêneo do qual emergem novas questões sobre a urbanização, que impulsiona estudos sobre áreas não metropolitanas (Damiani, 2006), que não menos importantes passam a atrair investimentos, população e serviços, exercendo centralidade (Spósito, 1998), sem com isso se tornar uma metrópole. É com base nestas condições que surgem diferentes pesquisas sobre cidades médias, como as preconizadas por Spósito (1991, 1998, 2007), Corrêa (1995, 2011), Santos e Silveira (2001), entre outros. Paralelamente, ocorre a concentração de estudos acadêmicos sobre metrópoles e cidades médias cuja justificativa reside na complexidade dos espaços urbanos, e pela concentração de centros de ensino e pesquisa, editoras e revistas nestas classes de cidades (Clancey, 2004). Clancey (2004) denuncia ainda que na América, em particular o tema das cidades pequenas foi alienado em função de interesses acadêmcos.

Tais condições do desigual processo de urbanização, e da atual globalização, têm reflexo sobre as cidades pequenas que sofrem com a perda populacional e o reduzido investimento que responde a baixa atratividade. Se antes elas eram responsáveis pela dinâmica sócio-espacial do território nacional (Corrêa, 2011; Endlich, 2011), atualmente desempenham papel marginal subordinado aos desígnios dos impulsos globais. Nestas condições, a cidade pequena funciona como receptáculo de ações de uma grande empresa ou de políticas compensatórias.

Ao nível analítico o estudo de cidades pequenas enfrenta dificuldades pelos limites apresentados pelo tradicional recurso ao tamanho populacional, cidades com até 50 mil habitantes segundo o IBGE. Por esta razão, Bell e Jayne $(2006,2009)$ denunciam as dificuldades no trato de cidades pequenas para além dos números absolutos apresentados pelo tamanho populacional, advertindo que a cidade pequena só é assim conceituada em comparação a outra cidade, evidenciando o problema causado pelo recurso ao tamanho populacional como fundamento do estudo cidades. O questionamento do recurso ao tamanho populacional para a classificação de cidades em geral, e de cidades pequenas em particular, produz avanços visíveis nas recentes classificações que conjugam tamanho e função na hierarquização de cidades (IPEA, IBGE e UNICAMP, 2001; IBGE, 2008). Por outro lado, a dificuldade reside em analisar a cidade pequena para além do trato como evidência empírica. Para Clancey (2004) o que ocorre é que a valorização de estudos sobre grandes cidades e o menosprezo em torno das pequenas, muitas vezes até desconhecidas, é algo que está enraizado na literatura das ciências sociais, bem como na própria cultura popular.

Bell e Jayne (2009) a realizar a critica sobre a valorização de estudos de grandes e médias cidades sinalizam que embora o mundo tenha um punhado de metrópoles globais, a principal característica do mundo urbano é justamente a heterogeneidade, que não se restringe a estudos metropolitanos ou às cidades globais. Os autores evidenciam que ainda que as cidades globais sejam importantes centros no atual contexto da globalização, as cidades pequenas também contribuem de alguma maneira ao processo de globalização. E reconhecem que embora no mundo todo, a maior parte da população vive em cidades, estão concentradas em pequenas e médias cidades ao redor do mundo.

Assim, a consolidação do fenômeno de urbanização implica em considerar como para cada parcela do território nacional, a cidade pequena experimenta especificidades no seu papel dentro do processo de urbanização. Para tanto, implica em considerar o contexto espacial como ferramenta metodológica para evidenciar e diferenciar cidades pequenas possibilitando enxergar o que de específico há em cada cidade pequena.

\section{A REDE URBANA}

Os estudos de rede urbana focalizam na definição e análise de variáveis para classificar, organizar e hierarquizar diferentes tipos de cidades, caracterizando os padrões espaciais (Corrêa, 2010). A escala de apreensão da cidade pequena torna-se elemento indispensável para nortear a análise. Assim, para a classificação de cidades segundo a escala da rede urbana, concorrem paralelamente: tamanho demográfico e função exercida. Tal posicionamento é claro nos estudos apresentados pelo IBGE $(2001,2008)$, que apontam para uma tradicional tendência nas classificações de rede urbana como afirma Corrêa (2000).

O tamanho populacional é variável recorrente em classificação de cidades, posto que "sem limites precisos, o contingente populacional é um elemento expressivo para determinar os aspectos formais da cidade", afirmam Geiger \& Davidovich (1961, p. 264). Desse ponto de vista, a cidade pequena é historicamente 
classificada segundo o seu tamanho, como salientam estudos de Rondinelli (1983), Bell \& Jayne (2006, 2009), Capel (2009), Sposito e Silva (2014). No Brasil, esse fato é constatado quando tomamos estudos clássicos sobre a rede urbana como aqueles desenvolvidos por Deffontaines (1944), Silva (1946), Geiger e Davidovich (1961).

Tomando por referência o tamanho da população a cidade pequena é aquela que não supera 50.000 habitantes para o Brasil (Corrêa, 1999; Santos e Silveira, 2001; Fresca, 2001). Para Sposito e Silva (2014) ainda que o quantitativo populacional seja limitador da análise sobre cidade pequena, não pode ser desqualificado. Como afirma Santos (2008, p. 134): "o efeito do tamanho tem papel na divisão interurbana e também na divisão intra-urbana do trabalho". Assim, o tamanho populacional abre caminhos para diferentes análises, mas perde valor se tomado como principal variável de classificação. Estudos recentes sobre cidades pequenas no Brasil consideram o tamanho populacional, porém incluem outras variáveis como em Melo (2008), Silva (2011), Sposito e Silva (2014).

Se o tamanho populacional não esgota a análise, é preciso considerar a cidade pequena segundo a função desempenhada, que está em estreita relação com os circuitos da economia. Santos (2008b) define que a economia das cidades em países subdesenvolvidos é formada por dois circuitos, sendo um superior e outro inferior.

Para Santos (2008b) o circuito superior, formado pelos setores mais modernos da economia, atua para atender aos impulsos globais, para o qual é destacado o papel das multinacionais e do Estado, junto às técnicas de transmissão instantânea de capital e informação. O circuito inferior "corresponde às transações diárias e à escala urbana" (Santos, 2007, 133) variando de acordo com o tamanho e influência da cidade; é aquele composto pelo homem lento, cuja economia é expressa no terciário e no comércio não-moderno, e abrigam aqueles desprovidos de capital e qualificação profissional.

A função como variável para análise de cidade pequena no Brasil ganha relevo em estudos realizados por Fresca (2001, 2010), Melo (2008), Endlich (2011), Fresca e Veiga (2011), Silva (2011), Moreira Junior (2014), Sposito e Silva (2014) e outros. Responde ao "deslocamento geográfico da importância das aglomerações e a mudança dos tipos de relação mantidos entre as aglomerações de diferente nível" (Santos, 1967, p. 78). O deslocamento do eixo tem como referência o aumento e diversificação do consumo que é resultado da complexidade do sistema de trocas como assinala Santos (1967). Responde ainda às transformações engendradas pelo processo de globalização, que ao refletir sobre o território, redefine a função exercida pelos diferentes centros urbanos.

A função desempenhada por dada cidade exige identificar o nível de centralidade e a influência exercida dentro do sistema de cidades que está em associação ao aprofundamento da globalização (Santos, 2008a, 2008b). A centralidade diz respeito à capacidade de um determinando centro em exercer influência, caracterizando um lugar central (Bessa, 2012). É justamente com o avanço das redes técnicas, o aumento dos fluxos informacionais garantido pela consolidação do meio técnico-científico-informacional (Santos, 2008c), internacionalização da economia, e ampliação do poder do capital multinacional que ocorre requalificação da centralidade tanto no nível inter como intra-urbano (Sposito, 1991). Com isso, todas as cidades exercem algum tipo de centralidade expressa no sistema de cidades.

Considerando a função desempenhada a cidade pequena é "um núcleo dotado da função de sede municipal" e "um centro que exerce centralidade em relação ao seu território municipal, sua hinterlândia" (Corrêa, 2011, p. 6/7). Assim, entre tantas possibilidades, a cidade pequena "pode ser melhor definida em termos do grau de centralidade do que em termos de tamanho demográfico. Ela se caracteriza por ser um centro local" (Corrêa, 2011, p. 6). Na mesma direção Rondinelli (1983, p. 385) destaca que "o valor dos pequenos centros urbanos não está tanto em suas dimensões populacionais como em suas características funcionais".

\section{CONTEXTO ESPACIAL E A CIDADE PEQUENA}

Se diferentes ações verticais e horizontais produzem especificidades no território, conjugada a ação de forças centrífugas e centrípetas, formatam o que estamos chamando de contexto espacial. Esta noção surge do reconhecimento de que a ação e interação de diferentes forças no território ao longo do tempo formatam condições espaciais que resultado da formação socioespacial (Santos, 1977), permite compreender, prever e antever ações e inclinações a que dado território estará sujeito. O contexto espacial permite ainda evidenciar os conteúdos e impulsos a que cada cidade está submetida, requalificando, consequentemente, o sistema de cidades e a organização do espaço urbano. 
O contexto espacial responde a generalidades, das quais a globalização é a maior determinante, onde é nodal o poder da informação que é também estratégico (Raffestin, 1993). Por outro lado, o contexto espacial responde a particularidades posto que para cada parcela do território a globalização tem uma materialidade e significado, o que quer dizer que cada parcela do território ganha uma especificidade como reflexo dos impulsos globais. São estes conteúdos e tais respostas que permitem compreender as diferenças entre cidades, e como estas, na sua dimensão interna mudam/adaptam-se garantindo o aprofundamento da globalização (Santos, 2008b). Em outras palavras, trata-se de compreender de que maneira os fatos, orquestrados por atores em distintas escalas, e num contexto que é tanto geral quanto particular, (re)qualifica a cidade na escala da rede, e por outro lado o urbano. Por esta razão o recurso ao contexto espacial como procedimento metodológico capaz de evidenciar diferentes aspectos da cidade se justifica seja no plano da rede urbana e no espaço urbano.

É mais que considerar a hintelândia, como bem explicam os teóricos das redes urbanas, mas trata-se de refletir como determinadas condições sobre o território formatam um contexto espacial que reflete diretamente sobre as funções, inclinações, serviços e atividades desenvolvidas pelas cidades. A análise da cidade, qual seja a escala de análise, exige a consideração do contexto espacial que emerge como uma ferramenta analítica capaz de desvendar ações, práticas, decisões que influem diretamente sobre 0 território, e que dão significado às lógicas que operam em dada realidade.

Moreira Junior (2014, p. 61) argumenta que "pesquisas teórico-conceituais e empíricas, em diferentes contextos, podem fornecer tanto abordagens comparativas quanto ao estabelecimento de uma agenda comum para a compreensão das cidades e da vida urbana". Para o autor situar o contexto além de ser um recurso metodológico, diz muito da configuração interna e das relações a que as cidades pequenas estão submetidas. De igual maneira, Capel (2009, p. 13) ao analisar o papel das cidades pequenas, orienta que al hablar de la localización de lãs pequeñas ciudades conviene distinguir asimismo, al igual que en las medias, entre dos tipos fundamentales: uno, las que se encuentran aisladas y son centro de un área de influencia, actuando como verdaderas capitales subregionales. Otro, las que, sea cual sea su evolución anterior, están hoy integradas en espacios metropolitanos coordinados por una ciudad de gran tamaño. Finalmente, se pueden considerar las que están integradas en áreas urbanas organizadas a lo largo de un eje de comunicación, configurando un área urbana polinuclear.

Deste ponto de vista, utilizamos dois vetores que definem o contexto espacial a saber: urbano-industrial e agroindustrial. O estabelecimento dos vetores como parâmetro de análise contribui como ponto de partida a entender a formação socioespacial, e consequentemente a própria cidade pequena. Significa considerar como alerta Santos (2008b, p. 32) que "as diversas ecologias locais não são unicamente explicáveis por fatores exclusivamente locais". Isto requalifica a cidade pequena no seu papel na rede urbana, dando novo sentido ao urbano, que para cada contexto é heterogêneo e específico.

\subsection{URBANO-INDUSTRIAL}

O contexto urbano-industrial no Brasil, noção que forjamos considerando a proposta realizada por Corrêa (2011), está em estreita relação com a modernização do território. Com a necessidade de participar mais ativamente na economia global, a modernização do território torna-se um processo inadiável, sendo responsável pelo comando das transformações processadas no Brasil desde a segunda metade do século XX (Becker e Egler, 1998; Santos, 2008b). A origem da modernização é resultado da ação de forcas que tem marco no impulso da industrialização. Recentemente, outra frente de modernização tem lugar na figura da (re)estruturação tecnológica que é resultado da nova divisão social e territorial internacional do trabalho (Oliveira, 2008). Tanto a industrialização como a reestruturação tecnológica são produto e condição da globalização que orienta transformações nas práticas espaciais.

A modernização ao expandir-se no território brasileiro impõe alterações diversas que incluem desde infraestrutura física à qualificação humana. A expressão avançada desse processo no Brasil é o Sudeste do país com extensão ao Sul, também chamada de região concentrada (Santos e Ribeiro, 1979). Nessa parcela do território acontece (i) o alargamento da urbanização, (ii) forte participação do Estado na criação de políticas de infraestrutura, (iii) consolidação da rede informacional. É também onde estão (a) sedes corporativas de empresas com capital internacional (Santos, 2009), (b) melhor rede de comunicação (rodovias, aerovias, infovias, ferrovias), (c) maiores e mais bem equipados centros de ensino e pesquisa, (d) para onde converge boa parcela dos recursos públicos (Becker e Egler, 1998; Tunes, 2015). Tais condições formatam um contexto urbano-industrial que incorpora de forma seletiva e desigual partes do Brasil e setores da sociedade - econômico, social, cultural, espacial. 
Cidades pequenas localizadas nesse contexto espacial participem de uma economia - urbana, industrial e financeira -, partilhando de um sistema de fluxos que resulta em profundas alterações do ponto de vista do papel da cidade, e no plano intra-urbano, no cotidiano. Além disso, na cidade pequena submetida a esse contexto é destacado o papel de grandes indústrias tanto a nível local e regional. São exemplos dessa dinâmica cidades pequenas da região de Presidente Prudente que estuda Silva (2011), ou do Médio Vale do Paraíba Fluminense (Oliveira, 2008).

Cidades pequenas no contexto urbano-industrial tendem a não ser extensão do campo modernizado. Logo, não desempenham função de confluência urbano-rural. Ao contrário, sua população economicamente ativa está distribuída nos setores secundário e terciário da economia. Tais características são evidente em Piraí (RJ), uma cidade pequena situada no Médio Vale do Paraíba Fluminense, onde a AMBEV indústria cervejeira, a Youtility Telemarketing e a Administração Pública absorvem a mão de obra local, determinando os rumos das políticas locais.

Outra característica é a requalificação do sentido de cidade pequena, especialmente porque a velocidade das transformações territoriais, econômicas e sociais é guiada pela lógica industrial e pelo capital cuja referência não é o local. Isso garante a ampliação do consumo norteado por externalidades, aprofundando o ritmo da globalização. Nessas condições a vida e cotidianidade estão em constante tensão com os impulsos globais, cuja expressão é revelada nos espaços de sociabilidade requalificados em decorrência dos novos conteúdos a que a cidade pequena está submetida no contexto urbano-industrial.

\subsection{AGROINDUSTRIAL}

A modernização do território aprofunda-se graças ao meio técnico-científico-informacional (Santos, 2008c) que garante que o território nacional seja incorporado ao sistema produtivo global, participando ativamente na nova divisão territorial e internacional do trabalho. Tais condições emergem em contextos urbanoindustriais, e expande-se para o campo. A capilaridade do processo assegura a incorporação do campo fortemente transformado em decorrência da tecnicização ampliada que tem a expressão mais moderna no sistema agroindustrial.

No campo modernizado há a introdução de maquinário de última geração, tecnologias diversas, que contribuiu a formação de novas racionalidades que resultam na passagem da paisagem rural a uma paisagem agrícola (Santos, 2008a). Com isso, ocorre a formação de complexas áreas agroindustriais, como pontuam Becker e Egler (1998) e Corrêa (2011), transformando as formas de produção no campo, e consequentemente, as relações que nele se estabelecem (Elias, 2003, 2006; Alves, 2006).

A racionalidade do processo de modernização no campo impõe a introdução no sistema produtivo de insumos que permitem o aumento da produtividade, como acontece na área de Cerrado. Amplia-se a fronteira agrícola (Becker e Egler, 1998) onde "o campo se adapta, metamorfoseia-se com relativa facilidade às demandas da formação espacial da qual faz parte" (Corrêa, 2000, p. 125), acentuando a "especialização de tarefas no território, segundo uma vasta tipologia das produções" (Santos, 2008a, p. 43).

Nesse contexto espacial o ritmo do campo modernizado faz com que surjam novos atores e instituições no cenário urbano de cidades pequenas, como o bancário, empresas de suporte ao produtor rural. Como afirma Santos (2008a), o homem do campo é substituído pelo bóia-fria, veterinário, técnico agrícola, profissional cada vez mais especializado (Santos, 2008a), processo que vem acontecendo com intensidade nas áreas de Cerrado como estudam Elias (2006) e Bernardes e Brandão Filho (2009).

Cidades pequenas submetidas à influência do contexto agroindustrial desempenham o papel de confluência urbano-rural como propõe Corrêa (2011). Em outras palavras, a principal função das cidades pequenas subjacentes a tal contexto é de intermédio das ações que se dão no campo, como ocorre em Formosa do Rio Preto (BA), onde a economia da soja norteia a produção no campo e os processos no espaço urbano. Outro caso de destaque é a cidade pequena de Uruçuí (PI) onde a Bunge Alimentos monopoliza a produção que acontece no campo. Além disso, porque ser portadora da esperança de emprego orienta a racionalidade das ações sociais no espaço urbano (Alves, 2006).

Nestas condições, assinala Rondinelli (1983), as cidades pequenas são cruciais ao estímulo do desenvolvimento rural, porque conseguem "oferecem economias de escala para uma ampla variedade de atividades sociais e econômicas básicas, organizam as economias de seus hinterlands, dão acesso às populações rurais a serviços e instalações básicas, bem como a mercados, serviços" (Rondinelli, 1983, p. 
381). Por sua vez, cidades pequenas submetidas ao contexto agroindustrial são cidades cuja temporalidade é diferenciada, formatando uma cidade lenta como sugerem Mayer e Knox (2006). Porquanto, o cotidiano de cidades pequenas neste contexto espacial é, semelhamte ao contexto urbano-industrial, composto de práticas espaciais definidas por relações de proximidade, familiaridade e vizinhança justapostos a práticas delineadas pelos impulsos do atual sistema produtivo agroindustrial.

\section{CONSIDERAÇÕES FINAIS}

A consolidação da urbanização e o aprofundamento da globalização implicam em substanciais alterações espaço-temporais, materializadas no território produzindo uma heterogeneidade cujos reflexos são visíveis nas cidades tanto na estrutura do sistema de cidades como no espaço urbano. Do conjunto de ações e reações sobre o território impulsionados pela urbanização e pelos avanços da globalização ocorre a formação de contextos espaciais responsáveis por conjugar forças e ações no território com forte impacto sobre as cidades.

Os avanços alcançados por diferentes estudos de cidades para além do tamanho populacional encontram na função desempenhada pelos centros urbanos um caminho para a análise de cidades. Não obstante, a função desempenhada está em simetria com aos usos do território, que responde também ao contexto espacial. Isto justifica a produção de especificidades diante de um sistema urbano heterogêneo, que na escala da cidade pequena abre espaço a novas questões analíticas.

Submetidas a determinados contextos espaciais as cidades, em geral, e as cidades pequenas, em particular, mudam de conteúdo o que requalifica a zona de influência exercida e as práticas desenvolvidas no espaço urbano. Implica numa mudança de eixo analítico, que além de considerar a rede urbana e o espaço urbano, considera o contexto espacial, de modo a construir um mosaico analítico capaz de revelar detalhes e generalidades existentes na cidade.

Em outras palavras, falar de cidade pequena situada no interior do Nordeste, ou em áreas de Cerrado como no Mato Grosso, Tocantins ou Oeste da Bahia, submetida ao contexto agroindustrial, não é a mesma coisa de falar de uma cidade pequena situada no eixo Rio - São Paulo subjacente ao contexto urbano-industrial. Os impulsos, fluxos e relações a que tanto uma cidade como outra estão inclinadas são diferentes, o que implica em diferenciar ao nível conceitual as duas realidades urbanas seja ao nível da rede urbana ou do espaço urbano. Esta diferenciação possibilita ainda revelar os sentidos da ação de diferentes atores nas cidades pequenas, desde aqueles identificados com o aparelho de Estado, capitalistas que resolvem instalar suas empresas - ou suas filiais -, até o homem comum com suas relações, práticas, conteúdos.

\section{REFERÊNCIAS}

BECKER, B. Tendências de transformação do território no Brasil: vetores e circuitos. Território, 1997 , 5-17.

CAPEL, H. Las pequeñas ciudades en la urbanización generalizada y ante la crisis global. Investigaciones Geográficas, 2009, 7-32.

CLANCEY, G. (2004). Local Memory and Worldly Narrative: The Remote City in America and Japan. Urban Studies , 41 (12), 2335-2355.

CORREAA, R. L. (2011). As pequenas cidades na confluência do urbano e do rural. GEOUSP - Espaço e Tempo , 05-12.

CORRÊA, R. L. (1999). Globalização e reestruturação da rede urbana: uma nota sobre as pequenas cidades. Território (6), 43-52.

CORRÊA, R. L. (1995). O espaço urbano. São Paulo: Ática.

CORREAA, R. L. (1996). Os centros de gestão do território:. Território , 23-30.

CORRÊA, R. L. (2011). Perspectivas da urbanização brasileira - uma visão geográfica para o futuro próximo. In: E. M. Pereira, \& L. C. Dias, As cidades e a urbanização no Brasil. Florianópolis: Insular.

CORRÊA, R. L. (2000). Rede Urbana e Formação espacial - uma Reflexão Considerando O Brasil. Território , 121-129.

DAMIANI, A. L. (2006). Cidades médias e pequenas no processo de globalização. Apontamentos bibliográficos. In: A. I. Lemos, M. ARROYO, \& M. L. SILVEIRA, América Latina: cidade, campo e turismo (pp. 135-147). São Paulo: CLACSO.

DEFFONTAINES, P. (1944). Como se constituti no Brasil a rede de cidades. Boletim Geográfico , 15 (II), 299-307.

ELIAS, D. (2003). Globalização e Agricultura. São Paulo: Edusp.

ELIAS, D. (2006). Globalização e fragmentação do espaço agrícola do Brasil. Scripta Nova. Revista electrónica de geografía y ciencias sociales . 
ENDLICH, A. M. (2011). O estudo das pequenas cidades e os desafios conceituais: áreas de comparabilidade e complexidade mínima. Huellas (15), 149-165.

FRESCA, T. M. (Dezembro de 2010). Centros locais e pequenas cidades: diferenças necessárias. Mercator ,75-81.

FRESCA, T. M. (2001). Em Defesa dos Estudos das Cidades Pequenas no Ensino de Geografia. Geografia , 10 (1), 27-34.

FRESCA, T. M., \& VEIGA, L. A. (2011). Pequenas cidades e especializações funcionais: o caso de Santa Fé - PR. Sociedade e natureza, 387-396.

GEIGER, P., \& DAVIDOVICH, F. (1961). Aspectos do fenômeno urbano no Brasil. Revista de Geografia Brasileira , 263-362.

HENRIQUE, W. (2010). Diferenças e repetições na produção do espaço urbano de cidades pequenas e médias. In: D. M. LOPES, \& W. HENRIQUE, Cidades médias e pequenas: teorias, conceitos e estudos de caso (45-58). Salvador: SEI.

IBGE, I. B. (2008). Regiões de influência de cidades (2007). Rio de Janeiro: IBGE.

IPEA, IBGE, \& UNICAMP. (2001). Caracterização e tendências da rede urbana do Brasil : configurações atuais e tendências da rede urbana. Brasília: IPEA.

MAIA, D. S. (2010). Cidades médias e pequenas do Nordeste: conferência de abertura. In: D. M. LOPES, \& W. HENRIQUE, Cidades médias e pequenas: teorias, conceitos e estudos de caso (pp. 13-38). Salvador: SEI.

MOREIRA JUNIOR, O. (2014). As cidades pequenas na região metropolitana de Campinas - SP: dinâmica demográfica, papéis urbanos e (re)produção do espaço. Tese de doutorado . Rio Claro: Universidade Estadual Paulista.

RAFFESTIN, C. (1993). Por uma geografia do poder. São Paulo: Ática.

ROCHEFORT, M. (1961). Métodos de Estudo das Rêdes Urbanas. Boletim Geográfico , 3-18.

RONDINELLI, D. A. (1983). Towns and Small Cities in Developing Countries. Geographical Review , 379395.

SANTOS, M. (1993). A urbanização brasileira. São Paulo: Hucitec.

SANTOS, M. (2004). O Espaço dividido: Os Dois Circuitos da Economia Urbana dos Países Subdesenvolvidos. São Paulo: Edusp.

SANTOS, M., \& RIBEIRO, A. C. (1979). O Conceito de Região Concentrada. Rio de Janeiro: UFRJ.

SANTOS, M., \& SILVEIRA, M. L. (2001). O Brasil - território e sociedade no início do século XX. Rio de Janeiro: Record.

SINGER, P. (1973). Economia política da urbanização. São Paulo: Brasiliense.

SPÓSITO, M. E. (1998). A gestão do território e as diferentes escalas da centralidade urbana. Território , 2737.

SPÓSITO, M. E. (1991). O chão arranha o céu: a lógica da reprodução monopolista da cidade. Universidade de São Paulo, Programa de Pós-graduação em Geografia Humana. São Paulo: Universidade de São Paulo. SPÓSITO, M. E. (2007). O estudo das cidades médias brasileiras: uma proposta metodológica. In: M. E. SPÓSITO, Cidades médias: espaços em transição. São Paulo: Expressão Popular.

SPÓSITO, M. E. (2009). Para pensar as pequenas e médias cidades brasileiras. Belém: FASE/UFPA.

TUNES, R. H. (2015). Geografia da Inovação: território e inovação no século XXI. Tese de doutorado . São Paulo: Universidade de São Paulo.

WHITACKER, A. M. (2010). Campo e cidade. cidades médias e pequenas. algumas proposições para a pesquisa e o debate. In: D. M. LOPES, \& W. HENRIQUE, Cidades médias e pequenas: teorias, conceitos e estudos de caso (187-194). Salvador: SEl. 